\title{
Shear strengths of aluminium nitride and titanium diboride under plane shock wave compression
}

\author{
D.P. Dandekar
}

\author{
U.S. Army Research Laboratory, Materials Directorate, Watertown, Massachusetts 02172-0001, U.S.A.
}

\begin{abstract}
Resume - On fait la comparaison des estimations des contraintes en paralleles la nitrure de l'alumnium et la diborure de titane obtenues (a) par des measures simultanees de contraintes longitudinales et laterales par moyen d'u indicateurs manganins sous engagement d'un choque d'ondulation plane (b) avec ceux calcules des declenchements entre le hydrodynamique et le choque Hugonoit de ces materiaux. Le resultat de ce travail fait voir que quoique les estimees des contraintes en paralleles obtenues par ces deux methodes pour le diboure de titane sont les memes pour le diboure, ceux de la nitrure de l'aluminium ne le sont pas. Ceci est au moins partiellement attribue' a la inconsistence observe entre les mesures simultanees des contraintes longitudinales et laterales dans la nitrure d'aluminium.
\end{abstract}

\begin{abstract}
This work compares the estimates of shear strengths of aluminium nitride and titanium diboride obtained (a) from the simultaneous measurements of longitudinal and lateral stress by means of manganin gauges under plane shock wave loading with (b) those calculated from the offset between hydrodynamic and shock Hugoniot of these materials. The results of this work show that whereas the estimates of the shear strength obtained by these two methods for titanium diboride are consistent with one another, those of aluminium nitride are not. This is at least partly due to the observed inconsistency between the simultaneous measurements of longitudinal and lateral stresses in aluminium nitride.
\end{abstract}

\section{INTRODUCTION}

Shear strength of a solid under plane shock wave loading is determined from: (i) measurements of longitudinal and shear wave velocities at a given shock compressed stress state, i.e. shear stress - shear strain under oblique impact loading conditions or, (ii) simultaneous measurements of longitudinal and lateral stresses under normal impact or, (iii) calculation of the difference between the shock Hugoniot stress and mean stress under uniaxial strain loading at a given value of strain, i.e. volume change. The values of shear strength as a function of stress increase in a predictable way up to and including the Hugoniot Elastic Limit (HEL) of a solid. At stresses larger than the HEL the values of shear strength may remain constant, increase or decrease with an increase in the values of stress in a non-transforming solid. Recent Hugoniot measurements, lateral stress measurements and equation of states obtained from ultrasonic longitudinal and shear wave velocity measurements at elevated pressures on aluminium nitride, i.e. AlN [1,2], and titanium diboride, i.e.TiB $2[3,4]$ permit one to calculate and compare these estimates of shear strengths obtained from the methods (ii) and (iii), respectively. Such a comparison is necessary to validate the lateral stress measurements made with manganin gauges for two reasons. First, recent analysis by Wong [5] indicate that the response of lateral stress gauges are dependent both on the matrix material in which it is embedded as well as the emplacement technique used. Additionally, since the conservation relations of linear momentum, energy and mass governing one dimensional wave propagation in a medium does not involve the lateral stresses, calibration of lateral stress gauges is not universal. It is equally important for such a comparison to establish that the hydrodynamic compression of a solid at elevated pressures, obtained from the ultrasonic wave velocity measurements at relatively low hydrostatic pressures, is representative of its behavior. 


\section{HYDRODYNAMIC COMPRESSION}

\subsection{Procedure to Obtain Hydrodynamic Compression}

Hydrodynamic compressions of $\mathrm{AlN}_{\mathrm{N}}$ and $\mathrm{TiB}_{2}$ were generated from the transit time measurements of longitudinal and shear waves to $0.7 \mathrm{GPa}[2,4]$. The transit times of these waves were measured by an ultrasonic technique known as pulse echo overlap technique [6]. A Birch - Bridgman pressure cell system manufactured by Harwood, with a 50 - 50 pentane - isopentane pressure medium was used to generate pressure. The magnitude of hydrostatic pressure was measured by a calibrated manganin coil. The specimens were cubic in shape with a linear dimension of $1.298 \pm 0.002 \mathrm{~cm}$. The transit time measurements at high pressures were replicated several times for the longitudinal and the shear wave velocities. The ultrasonic transit times of longitudinal and shear waves were analyzed following an iterative scheme developed by Dandekar [7] to calculate the values of bulk and shear moduli of the materials and their respective pressure derivatives. The details of the ultrasonic experiments and of the analysis of the ultrasonic data are given in Ref. 2, 4, and 7.

The hydrodynamic compression curves of these materials are obtained by using the equation of state based on linear relationship between shock $(U)$ and particle $(u)$ velocities namely,

$$
\begin{aligned}
& \mathrm{U}=\mathrm{C}_{0}+\mathrm{su} \\
& \mathrm{P}=\rho_{0} \mathrm{C}_{0}^{2} \eta /(1-\mathrm{s} \eta)^{2}
\end{aligned}
$$

and

$$
\eta=1-\mathrm{V} / \mathrm{V}_{0}
$$

where $\rho, C$, and $V$ are density, bulk sound wave velocity, and volume, respectively. The subscript 0 denotes the initial values of the various parameters under the ambient condition. An additional relation required to construct the compression curve is that between $\mathrm{s}$ and the pressure derivative of the adiabatic bulk modulus $\left(\mathrm{K}_{0}{ }^{\prime}\right)$ derived by Ruoff [8] and is

$$
\mathrm{K}_{0}^{\prime}=4 \mathrm{~s}-1 .
$$

\subsection{Compression of Aluminium Nitride}

The material used in the investigations by Rosenberg et al. [1] and Dandekar et al. [2] was manufactured by Dow. The composition of the material (in weight \%) was : AlN (98.6), oxygen (1.0), and carbon (0.3). The hydrodynamic compression curve of AlN generated in the manner described above is shown in Fig.1. The values of bulk modulus and its pressure derivative for AIN obtained from the ultrasonic wave velocity measurements at high pressures on Dow material by Dandekar et al. [2] and on a purer AlN i.e., 99.99 \% by in-situ high pressure X-ray diffraction measurements to $18 \mathrm{GPa}$ of Xia et al. [9] are given in Table 1. The compression curves for AlN generated from these two data are shown in Fig.1. This figure shows that the compression curves of relatively pure AIN obtained in these investigations are consistent with one another and the differences are within the precision of the respective measurements on AIN. In addition, there is very little difference between the adiabatic and isothermal compressions of AlN.

\subsection{Compression of Titanium Diboride}

The hydrodynamic compressions of $\mathrm{TiB}_{2}$ obtained from the measurements of ultrasonic wave velocity measurements to $0.7 \mathrm{GPa}$ by Abbate et al.[4] and from the results of shock experiments carried out by Gust et al. [10] and reported by Marsh [11] have been examined earlier by Dandekar and Benfanti [12]. The main conclusion of this examination was that, whereas the values of the bulk modulus of $\mathrm{TiB}_{2}$ obtained from different sources were significantly different from one another, the values of their pressure derivatives were not. In other words, a representative hydrodynamic compression of $\mathrm{TiB}_{2}$ can be calculated from the value of the pressure derivative of the bulk modulus obtained from the ultrasonic wave velocity measurements at relatively low hydrostatic pressures, provided appropriate value of the bulk modulus was used in these calculations. A confirmation of this observation is shown in Fig.2 which illustrates the compression of $\mathrm{TiB}_{2}$ material manufactured by Cercom and used by Rosenberg et al. [3]. Its density was 


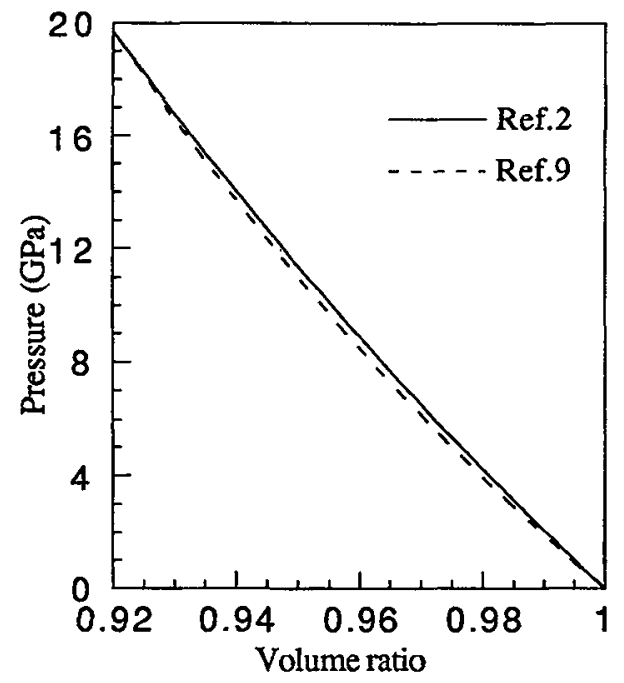

Figure 1. Compression of aluminium nitride.

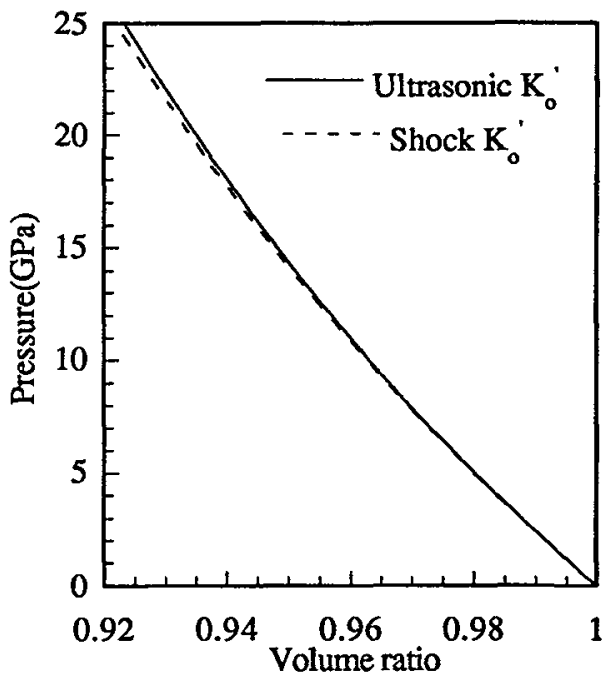

Figure 2. Compression of titanium diboride.

Table 1. Properties of Aluminum Nitride and Titanium Diboride.

\begin{tabular}{lccccc}
\hline & \multicolumn{2}{c}{ Aluminum Nitride } & \multicolumn{2}{c}{ Titanium Diboride } \\
Properties & Units & Reference 2 & Reference 9 & Reference 4 & Reference 10 \\
\hline Density & $\mathrm{Mg} / \mathrm{m}^{3}$ & $3.23 \pm 0.01$ & 3.255 & $4.49 \pm 0.01$ & $4.52 \pm 0.01$ \\
Bulk Wave Velocity & $\mathrm{km} / \mathrm{s}$ & $7.92 \pm 0.03$ & & $7.27 \pm 0.16$ & $7.39 \pm 0.37$ \\
Bulk Modulus & $\mathrm{GPa}$ & $202 \pm 2$ & $185 \pm 5$ & $238 \pm 10$ & $247 \pm 12$ \\
Pressure Derivative & & $3.68 \pm 0.62$ & $5.7 \pm 1.0$ & $2.02 \pm 0.18$ & $1.89 \pm 0.29$ \\
of Bulk Modulus & & & & & \\
\hline
\end{tabular}

$4.48 \mathrm{Mg} / \mathrm{m}^{3}$. The value of its bulk modulus was $232 \mathrm{GPa}^{1}$. The values of $\mathrm{K}_{0}{ }^{\prime}$ used in the calculations are obtained from the results of the ultrasonic and the shock wave experiments reported in Refs. 4 and 10 , respectively (Table 1 ).

\section{SHEAR STRENGTH}

\subsection{Procedure to Obtain Shear Strength}

Shear strength of a solid can be determined through the simultaneous measurements of longitudinal $\left(\sigma_{1}\right)$ and lateral $\left(\sigma_{2}\right)$ stresses under plane shock wave loading. Rosenberg et al. $[1,3]$ measured these stresses by using manganin foil gauges. The shear strength $(\tau)$ is thus simply the half the value of the difference in the measured values of $\sigma_{1}$ and $\sigma_{2}$. Another way to estimate the value of shear stress $(\tau)$ sustained by the material under plane shock wave loading is to calculate the difference between the magnitudes of shock stress i.e., longitudinal stress $\left(\sigma_{1}\right)$ and hydrodynamic pressure $(\mathrm{P})$ at a given value of strain i.e. volume change $(\eta)$. Estimates of shear strength $(\tau)$ of solid from its shock and the hydrodynamic compression curve obtained in this manner at a given compression/strain $(\eta)$ is given by Eq. (5) . 


$$
\tau=0.75 \times[\sigma(\eta)-\mathrm{P}(\eta)]
$$

\subsection{Shear Strength of Aluminium Nitride}

The values of shear strength under plane shock wave compression obtained from simultaneous measurements of longitudinal and lateral stresses by Rosenberg et al. [1], and from their shock i.e., longitudinal stress and the hydrodynamic compression obtained in the present work (Table 2) are plotted as a function of longitudinal stress in Figure 3. The measurements of Rosenberg et al. [1] show that values of shear stress / shear strength increase as the magnitude of longitudinal stress approach the value of the HEL, i.e., 9.4 $\pm 0.2 \mathrm{GPa}$ in AlN. The value of the shear strength at the HEL is $3.5 \pm 0.2 \mathrm{GPa}$. This value of

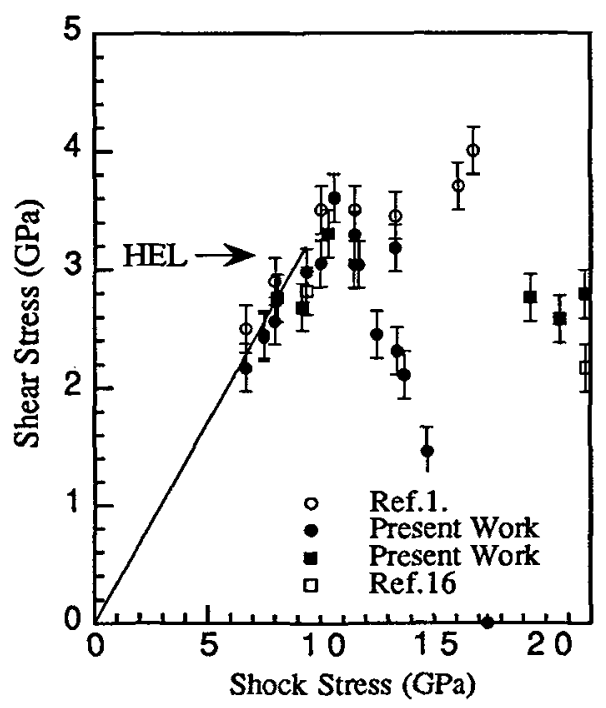

Figure 3. Shear strength versus shock stress in aluminium nitride.

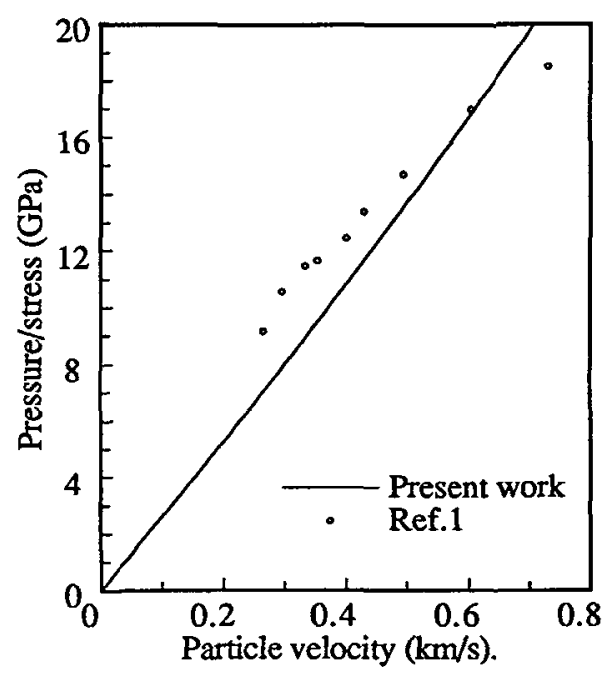

Figure 4. Stress/pressure versus particle velocity in aluminium nitride.

the shear stress is maintained in AlN at the higher stresses up to $16 \mathrm{GPa}$ and at a stress around $16.8 \mathrm{GPa}$ the shear strength increases to $4.0 \pm 0.2 \mathrm{GPa}$. This increase in the shear strength at $16.8 \mathrm{GPa}$ was suggested by these authors to be related to the phase transformation in AlN observed by Kondo et al. [13] and Vollstadt et al. [14] around $18 \mathrm{GPa}$ but these authors did not observe any evidence of phase transition in their experiments to $18 \mathrm{GPa}$. Thus the results of simultaneous measurements of the longitudinal and lateral stresses in the shock wave experiments led Rosenberg et al. to conclude that the deformation behavior of AlN is like that of an elastic - plastic solid. However the estimates of shear stress sustained by AIN as a function of longitudinal stress obtained from their measurements of the longitudinal stresses in Ref. 1 and the hydrodynamic compression of AlN reported here show that the shear strength of AlN increases with the increasing value of the longitudinal stress up to around $11 \mathrm{GPa}$ and then begins to decline, vanishing at around $18 \mathrm{GPa}$. These two results are radically different from one another. Since the reduction in the shear strength as a function of longitudinal stress implies that the shock Hugoniot is converging towards the hydrodynamic compression curve, it is natural to examine the Hugoniot of AlN determined by Rosenberg et al. [1]. This is accomplished here by plotting the measured values of longitudinal stress versus particle velocity for AIN from Table II given in Ref. 1 and the pressure-particle velocity locus obtained from our ultrasonic measurements. The advantage of such a comparison is that one does not have to perform any calculations on the data given in Ref. 1. The locus for AlN, i.e., pressure (P) - particle velocity (u) coordinates are obtained by using the momentum conservation relation i.e.,

$$
P=\rho_{0} U u=\rho_{0}\left(C_{0}+s u\right) u .
$$

This relation assumes the validity of Eq. (1). The values of density of $3.23 \mathrm{Mg} / \mathrm{m}^{3}$ and the bulk sound 
Table 2. Shock Data on Aluminium Nitride.

\begin{tabular}{|c|c|c|c|c|c|c|}
\hline $\begin{array}{l}\text { Longitudinal } \\
\text { Stress }^{1} \\
\text { (GPa) }\end{array}$ & $\begin{array}{c}\text { Particle } \\
\text { Velocity } 1 \\
(\mathrm{~km} / \mathrm{s})\end{array}$ & $\begin{array}{c}\text { Lateral } \\
\text { Stress } 1 \\
\text { (GPa) }\end{array}$ & $\begin{array}{c}\text { Shock } \\
\text { Velocity }^{2} \\
(\mathrm{~km} / \mathrm{s})\end{array}$ & $\begin{array}{l}\text { Volume } \\
\text { Ratio }^{2}\end{array}$ & $\begin{array}{c}\text { Hydrodynamic } \\
\text { Pressure }^{3} \\
\text { (GPa) }\end{array}$ & $\begin{array}{c}\text { Shear } \\
\text { Strength } 4 \\
\text { (GPa) }\end{array}$ \\
\hline $16.8 \pm 0.3$ & & $8.8 \pm 0.1$ & & & & \\
\hline $16.1 \pm 0.3$ & & $8.7 \pm 0.1$ & & & & \\
\hline $10.6 \pm 0.2$ & 0.296 & & $15.25 \pm 1.0$ & 0.973 & 5.79 & 3.61 \\
\hline $11.7 \pm 0.2$ & 0.354 & & $8.72 \pm 0.6$ & 0.9651 & 7.62 & 3.06 \\
\hline $12.5 \pm 0.2$ & 0.401 & & $7.52 \pm 0.5$ & 0.9585 & 9.21 & 2.47 \\
\hline $13.4 \pm 0.2$ & 0.43 & & $7.91 \pm 0.5$ & 0.9541 & 10.30 & 2.32 \\
\hline $14.7 \pm 0.3$ & 0.494 & & $7.48 \pm 0.5$ & 0.9446 & 12.73 & 1.48 \\
\hline $17.0 \pm 0.3$ & 0.605 & & $7.16 \pm 0.5$ & 0.9275 & 17.39 & -0.3 \\
\hline $18.5 \pm 0.5$ & 0.73 & & $6.27 \pm 0.4$ & 0.9002 & & \\
\hline $10.0 \pm 0.3$ & & $3.0 \pm 0.1$ & & & & \\
\hline $13.3 \pm 0.3$ & & $6.4 \pm 0.2$ & & & & \\
\hline $11.5 \pm 0.2$ & 0.335 & $4.5 \pm 0.1$ & $10.31 \pm 0.7$ & 0.9659 & 7.44 & 3.04 \\
\hline $6.7 \pm 0.1$ & & $1.7 \pm 0.1$ & & 0.9819 & 3.80 & 2.18 \\
\hline $7.5 \pm 0.1$ & & $2.6 \pm 0.1$ & & 0.9798 & 4.26 & 2.43 \\
\hline $8.0 \pm 0.1$ & & $2.2 \pm 0.2$ & & 0.9784 & 4.57 & 2.57 \\
\hline $9.4 \pm 0.2$ & & & & 0.9746 & 5.42 & 2.98 \\
\hline
\end{tabular}

1 Table II in Ref.1. ${ }^{2}$ Calculated from the data in Ref.1. ${ }^{3}$ Calculated using Eq.2. ${ }^{4}$ Calculated using Eq.5.

wave velocity of $7.90 \mathrm{~km} / \mathrm{s}$ used in these calculations are those given in Table I of Ref. 1 for AlN. The value of $s$ used is derived from the ultrasonic measurements discussed above. The value of $s$ is $1.17 \pm$ 0.155 (Table 1). This, then, represents the hydrodynamic states of AlN in pressure - particle velocity coordinates. Fig. 4 shows a plot of the measured values of longitudinal stress versus particle velocity in AlN reported in Ref 1 (Table 2) and the hydrodynamic pressure -particle velocity locus for AlN obtained from our ultrasonic measurements and through the use of $\mathrm{Eq}$. (6). Since the stress-particle velocity coordinates of AlN reported in Ref. 1 converge towards the hydrodynamic loci, it implies that AlN is sustaining a smaller magnitude of shear stress with an increase in the compressive stress. This result is consistent with the decreasing magnitudes of the shock velocities, above its HEL, i.e. $9.4 \mathrm{GPa}$, calculated from the shock data given in Ref. 1 and the values of the velocities at stresses $14.7 \mathrm{GPa}$ and above are smaller than the bulk sound wave velocity of $7.90 \mathrm{~km} / \mathrm{s}$ in AlN (Table 2). It has been shown by Graham and Brooks [15] that in a material undergoing a significant loss of shear strength under plane shock wave loading the values of shock velocity will be smaller than its bulk sound wave velocity. Thus the constancy of the shear strength values above the HEL calculated from the difference between the measured longitudinal and lateral stresses are inconsistent with their shock Hugoniot of untransformed AlN reported in Ref. 1. Grady [16] provided estimates of the shear strength and his shock Hugoniot data on the same AlN investigated by Rosenberg et al.[1]. He [17] reported a transition stress of $22 \mathrm{GPa}$ in AlN. Estimates of the shear strength obtained from his shock data and the hydrodynamic compression of AIN obtained in this work are $2.7 \pm 0.2 \mathrm{GPa}$ when the shock stress lies between 10 and $21.8 \mathrm{GPa}$. This is consistent with the values of shear strength between 2.2 and $2.8 \mathrm{GPa}$ reported by Grady [16] and shown in Fig. 3. This result implies that the shock Hugoniot reported in Ref.16 \& 17 maintains a finite offset from the hydrodynamic loci obtained in this work up to the transition stress of $22 \mathrm{GPa}$ in AlN unlike the data reported in Ref.1.

\subsection{Shear Strength of Titanium Diboride}

Shear strength of $\mathrm{TiB}_{2}$ calculated from the stress offset between the normal shock stress and the hydrodynamic curve at a corresponding compression has been reported by Dandekar and Benfanti [12]. These authors were aware of the work of Rosenberg et al. [3]. Since information needed to calculate the bulk modulus of their $\mathrm{TiB}_{2}$ was not then available, it was not possible to calculate the magnitudes of shear stresses sustained by their $\mathrm{TiB}_{2}$ and to compare them with their measured values of shear stresses at 
Table 3. Shear Strength of Titanium Diboride.

\begin{tabular}{lccccc}
\hline Shear Strength (GPa) & \multicolumn{5}{c}{ Shock Stress (GPa) } \\
& 6.8 & 10.0 & 19.5 & 24.0 & 19.5 \\
& & & & & \\
\hline Present work & 2.95 & 4.32 & 6.59 & 7.02 & 6.59 \\
Reference 3 & 2.95 & 4.25 & 6.70 & 7.45 & 6.20 \\
\hline
\end{tabular}

various stresses. The availability of the required information makes it possible to do such a comparison now. The estimates of shear stress sustained by $\mathrm{TiB}_{2}$ under compression obtained by these two methods are indistinguishable from one another (Table 3).

\section{CONCLUSION}

The present work shows that for $\mathrm{TiB}_{2}$ the estimates of shear strength obtained from the lateral and longitudinal stress measurements are consistent with the estimates of the shear strength obtained from the calculated offset between hydrodynamic and the Hugoniot at a given strain. However, this is not the case for A1N data in Ref.1 because the measured Hugoniot, above its HEL, converges towards the hydrodynamic loci intersecting it at $16.8 \pm 0.2 \mathrm{GPa}$. On the other hand, the Hugoniot of the same material reported in Ref.16 \& 17 maintains a finite offset from the hydrodynamic loci up to the transition stress 22 $\mathrm{GPa}$. Thus this work raises an important issue: assuming that this material is indeed deforming like an elastic-plastic solid below the transition stress, how is it possible to obtain a nearly constant magnitude of the shear strength from the difference between the measured values of the longitudinal/Hugoniot and lateral stresses reported in Ref. 1 when the Hugoniot is also converging towards the hydrodynamic loci?

\section{ACKNOWLEDGEMENT}

The author appreciates the assistance of P. Bartkowski and P. Moy in preparation of the manuscript and thanks Mr. Richard A. Bonneau for providing the French translation of the abstract.

\section{REFERENCES}

[1] Rosenberg Z., Brar N. S., and Bless S. J., J . Appl. Phys.70 (1991) 167-171.

[2] Dandekar D. P., Abbate A., and Frankel J., Presented at the U. S. Army Symposium on Solid Mechanics, 17 - 19 August, 1993, Plymouth, Massachusetts, USA.

[3] Rosenberg Z., Brar N. S., and Bless S. J., " Shear strength of titanium diboride under shock loading measured by transverse manganin gauges "Shock Compression of Condensed Matter-1991, Ed. S. C. Schmidt, R. D. Dick, J. W. Forbes, and D. G. Tasker (Elsevier, Amsterdam, 1992), 471-473.

[4] Abbate A., Frankel J., Dandekar D. P., "Pressure dependence of the elastic constants of polycrystalline titanium diboride" Trends in High Pressure Research, Ed. A. K. Singh (Oxford, New Delhi, 1992), 881883.

[5] Wong, M. K. W., "Experiments and analysis of lateral piezoresistive gauges in shocked solids", Presented at the AIRAPT/APS High Pressure Science and Technology Conference, Colorado Springs, Colorado, 28 June-2 July, 1993.

[6] Papadakis E. P., J. Acoust Soc. Am. 42 (1967) 1045-1051.

[7] Dandekar D. P., J. Appl. Phys. 41 (1970) 667-672.

[8] Ruoff A. L., J.Appl. Phys. 38 (1967), 4976-4980.

[9] Xia Q., Xia H. and Ruoff A. L., J. Appl. Phys. 73 (1993) 8198-8200.

[10] Gust W. H., Holt A. C., and Royce E. B., J. Appl. Phys. 44 (1973) 550-560.

[11] Marsh S. P.,LASL Shock Hugoniot Data (University of California Press, Berkeley,1980) 354.

[12] Dandekar D. P. and Benfanti D. C., J Appl. Phys. 73 (1993) 673-679.

[13] Kondo K., Sawaoka A., Sato K., and Ando M., Shock Waves in Condensed Matter-1981, edited by W. J. Nellis, L. Seaman, and R. A. Graham (American Institute of Physics, New York, 1982) 325 - 329.

[14] Vollstadt H., Ito E., Akaishi M., Akimoto S., and Fukunaga O., Proc. Japan Acad., 66 Ser.B 7 (1990) 7-9.

[15] Graham R. A., and Brooks W. P., J. Appl. Phys. 32 (1971) 2311-2330.

[16] Grady D., "Shock wave properties of high-strength ceramics" Shock Compression of Condensed Matter-1991, Ed. S. C. Schmidt, R. D. Dick, J. W. Forbes, and D. G. Tasker (Elsevier, Amsterdam, 1992), 455-458.

[17] Grady D., Private communication. 